\section{Novel Grafting Procedure of Ruthenium 2,2':6',2'-Terpyridine Complexes with Phosphonate Ligands to Titania for Water Splitting Applications}

Marcus Wasera , Christian Siebenhaara , Jennifer Zampese $^{b}$, Gerhard Grundlera, Edwin Constable ${ }^{b}$, Murray Height $^{c}$, and Uwe Pieles ${ }^{\star a}$

${ }^{\star}$ Correspondence: Prof. Dr. U. Pieles ${ }^{a}$, Tel.: +4161467 4453, Fax: + 41614674457 E-mail: uwe.pieles@fhnw.ch

aUniversity of Applied Sciences Northwestern Switzerland, School of Life

Sciences, Institute for Chemistry and Bioanalytics, Gründenstrasse 40

$\mathrm{CH}-4132$ Muttenz

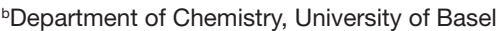

'HeiQ Materials, Bad Zurzach

Keywords: Ruthenium terpyridine complexes · Phosphonic acid linkers · Titanium dioxide grafting

\section{Introduction}

Power needs and the demand for carbon-neutral energy sources are growing both nationally and internationally. These challenges could be overcome simultaneously by the use of water-splitting cells in which sunlight is used as a sustainable energy source and hydrogen for chemical energy storage.

Sunlight-assisted electrolysis of water was first reported in 1972 by Fujishima and Honda ${ }^{[1]}$ using $\mathrm{TiO}_{2}$ as photoanode and platinum as cathode. One problem of using pure $\mathrm{TiO}_{2}$ as photoanode is that only the ultraviolet part of the solar spectrum is absorbed due to the large band gap of 3-3.2 eV. Other semiconductors with band gaps able to absorb the visible part of the spectrum are unstable against photo corrosion. A solution to this complexity was found when the $\mathrm{TiO}_{2}$ was dye-sensitized with a coloured material possessing a ground state below and an excited state above the conduction band of the semiconductor. By dyesensitizing, visible light is absorbed by the dye which forms a molecular excited state and the excited state may then inject an electron into the $\mathrm{TiO}_{2}$ conduction band causing charge separation. In the case of dye-sensitized solar cells confirmed efficiencies of $>10 \%$ have been reported. ${ }^{[2]}$ Because of the operating requirements of long-term stability in the presence of air, water and other additives in the system, metal-containing dyes are usually preferred over purely organic materials. Particular emphasis has been placed on the use of ruthenium dyes, which absorb from the green through to the near IR in some cases, containing oligopyridine ligands.

In order to produce a commercial product for the splitting of water, the production steps leading to the final product must be addressed. The dye used for sensitisation has to be produced and grafted onto the $\mathrm{TiO}_{2}$ in as few steps as possible. Commonly the grafting is done by reacting a carboxylic or phosphonic acid group of the dye with $\mathrm{TiO}_{2}$. We are particularly interested in phosphonic acid linkers and the conventional synthetic route involves conversion of the phosphonate ester to the phosphonic acid which is then used to graft onto the $\mathrm{TiO}_{2}$. By using the phosphonic ester to graft directly onto the $\mathrm{TiO}_{2}$, one reaction step could be avoided. Direct grafting of phosphonate esters onto different metal ox-

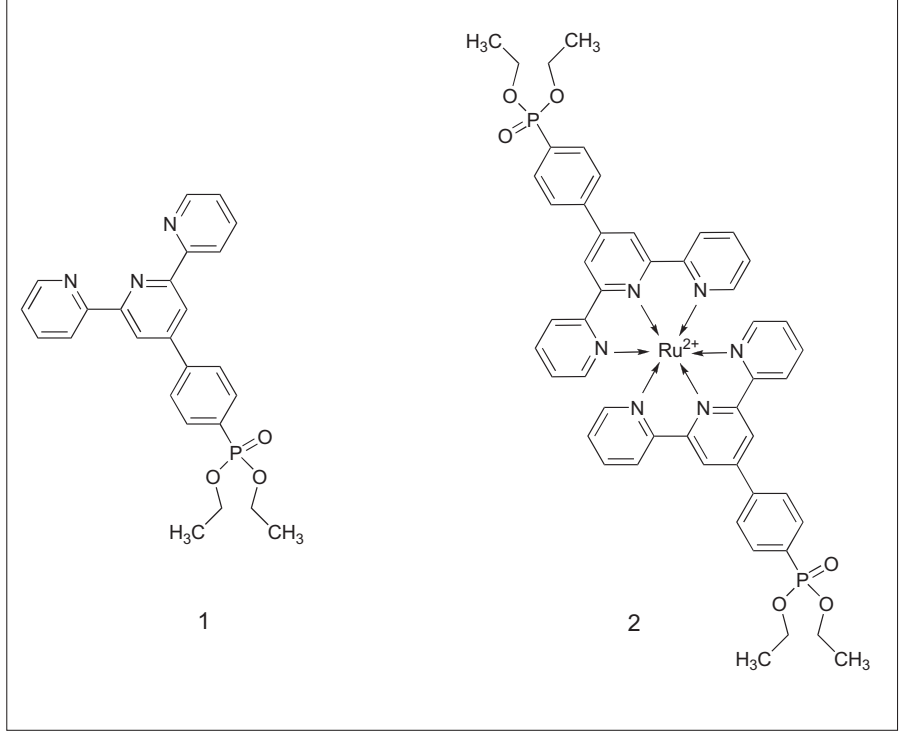

Fig. 1. Phosphonate ligand and the corresponding ruthenium dye for functionalisation of $\mathrm{TiO}_{2}$.

ides including $\mathrm{TiO}_{2}$ has been described earlier. ${ }^{[3]}$ We selected $2,2 ': 6$ ',2"'-terpyridine ligands containing phosphonate substituents in the first instance and describe here results with ligand 1 and the ruthenium dye 2 (Fig. 1).

\section{Results and Discussion}

Conventional functionalisation methods for $\mathrm{TiO}_{2}$ involve direct reaction with a complex bearing carboxylic acid or phosphonic acid functionality. The purification and characterisation of these species is often difficult because of i) uncertainties over the protonation state of the substituents and ii) the high water solubility. It is attractive to avoid the preparation of the free phosphonic acid species and we have now shown that it is possible to functionalise the $\mathrm{TiO}_{2}$ surface with either $\mathbf{1}$ or $\mathbf{2}$. Although $\mathbf{1}$ is colourless, we have developed convincing visual proof that the phosphonate ester can be grafted directly onto $\mathrm{TiO}_{2}$. The grafting was carried out using the procedure of Frantz et al. ${ }^{[3 a]}$ in which the ligand $\mathbf{1}$ is dissolved in 2-propanol and refluxed for five days with the $\mathrm{TiO}_{2}$. The excess of ligand is separated by centrifugation and repeated washing. 2,2':6',2'-Terpyridine ligands form stable and highly coloured $\left[\mathrm{FeL}_{2}\right]^{2+}$ complexes with iron(II) salts. The complexes are purple with an absorption maximum typically close to $550 \mathrm{~nm}$. When solutions of iron(II) salts are added to the functionalised $\mathrm{TiO}_{2}$ slurry, an immediate purple colour develops. The purple colour develops only on the solid and not in the supernatant establishing i) that the surface of the $\mathrm{TiO}_{2}$ has been modified with $\mathbf{1}$ and ii) that the complexes are irreversibly bound to the surface of the semiconductor.

Grafting of the dye $\mathbf{2}$ onto the surface proved to be more delicate. Using the same procedure as before, it took three weeks to graft only a very small amount of dye onto titania (weight ratio dye/titania $1: 100$ ). The unfavourable reaction time could be 
improved by carrying out the reaction under microwave heating. Several solvents and reaction conditions were tested for optimal surface modification. Of all the solvents tested, ethane-1,2-diol and also 1-butanol showed the best results. The yield using the ester complex $\mathbf{2}$ is not yet as high as when the corresponding acid is used for the reaction but the advantages in material preparation and characterisation are manifest. In the case of 1-butanol as a solvent, at high concentrations of $\mathbf{2}$ an insoluble ruthenium species is formed that we suspect is the zwitterionic complex of the monoester ligand.

In conclusion, we have found a viable alternative to the preparation of free phosphonic acids for the preparation of dye sensitised solar cells. We also note the subsequent metallation of the $\mathrm{TiO}_{2}$ modified with $\mathbf{1}$ should also lead to novel functional materials.

Received: March 24, 2010

[1] A. Fujishima, K. Honda, Nature 1991, 353, 737.

[2] M. Green, K. Emery, Y. Hishikawa, W. Warta, Prog. Photovoltaics: Res. App. 2008, 16, 61.

[3] a) R. Frantz, J.-O. Duranda, M. Graniera, G.F. Lanneau, Tetrahedron Lett. 2004, 45, 2935; b) G. Guerrero, P. H. Mutin, E. Framery, A. Vioux, New J. Chem. 2008, 32, 1519; c) G. Guerrero, P. H. Mutin, E. Framery, A. Vioux, Chem. Mater. 2001, 13, 4367. 